\title{
Scoliosis and bronchial obstruction
}

\author{
Mehdi Qiabi MD', Karine Chagnon $\mathrm{MD}^{2}$, Alain Beaupré $\mathrm{MD}^{2}$, Julian Hercun $\mathrm{MD}^{2}$, George Rakovich $\mathrm{MD}^{1}$
}

\begin{abstract}
M Qiabi, K Chagnon, A Beaupré, J Hercun, G Rakovich. Scoliosis
and bronchial obstruction. Can Respir J 2015;22(4):206-208.

Severe scoliosis may have a significant effect on respiratory function. The effect is most often restrictive due to severe anatomical distortion of the chest, leading to reduced lung volumes, limited diaphragmatic excursion and chest wall muscle inefficiency. Bronchial compression by the deformed spine may also occur but is more unusual. Management options include a conservative approach using bracing and physiotherapy in mild cases, as well as surgical correction of the scoliosis in more severe cases. Bronchial stenting has also been used successfully as an alternative to surgical correction, and in cases in which spinal surgery was either unsuccessful or not feasible. The authors present a case involving a 52-year-old woman who exhibited symptomatic compression of the bronchus intermedius by severe residual scoliosis despite previous corrective surgery. She was treated with an indwelling bronchial stent.
\end{abstract}

Key Words: Bronchial obstruction; Idiopathic scoliosis

Learning objectives:

- To understand the reasons for respiratory compromise in patients with severe scoliosis.

- To be familiar with the treatment of bronchial obstruction caused by severe scoliosis.

Can MEDS competency: Medical Expert

Pretest

- What is the most common cause of chronic dyspnea in patients with idiopathic scoliosis (IS)?

- What are the options for treating bronchial obstruction caused by scoliosis?

\section{CASE PRESENTATION}

A 52-year-old woman was referred to the authors' centre in 2003 for an unresolving pneumonia. She was known for severe IS treated surgically at 12 years of age. She was on albuterol/ipratropium combination (Combivent, Boehringer Ingelheim Pharmaceuticals, USA) and fluticasone (Flovent, GlaxoSmithKline, USA) inhalers for a clinical diagnosis of asthma, which, however, had not been substantiated by pulmonary function tests (PFTs). She also had a chronic, nonproductive cough but no chronic dyspnea. She had smoked one pack per day between 20 and 30 years of age. In the previous year, she had experienced at least five documented episodes of pneumonia; these had been diagnosed clinically and radiologically, although sputum cultures had been negative on several occasions.

Computed tomography of the chest revealed atelectasis and pneumonia of the right lower lobe and compression of the bronchus intermedius by a severe residual deformity of the thoracic spine (Figure 1A). Bronchoscopy revealed a significant stenosis of the bronchus intermedius (Figure 2A). There was no evidence of neoplasia. The pneumonia eventually resolved after a prolonged course of intravenous antibiotics, as documented clinically and radiologically.

PFTs conducted electively were essentially normal despite the known obstruction in the bronchus intermedius, likely explained by

\section{La scoliose et l'obstruction bronchique}

Une grave scoliose peut nuire considérablement à la fonction respiratoire. Elle a généralement un effet restrictif causé par l'importante distorsion anatomique du thorax qui réduit le volume pulmonaire et l'excursion diaphragmatique et qui rend les muscles de la paroi thoracique inefficaces. La déformation de la colonne vertébrale peut également imprimer une compression bronchique, mais c'est plus rare. Pour la prendre en charge, on privilégie une approche prudente incluant le port d'un appareil et de la physiothérapie dans les cas légers, de même qu'une correction chirurgicale dans les cas plus graves. L'installation d'une endoprothèse bronchique a également déjà remplacé la correction chirurgicale ou été favorisée lorsque celle-ci échouait ou n'était pas envisageable. Les auteurs présentent le cas d'une femme de 52 ans ayant une compression symptomatique de la bronche intermédiaire attribuable à une grave scoliose résiduelle, malgré une correction chirurgicale. Elle a été soignée par la pose d'une endoprothèse bronchique à demeure.

the fact that the obstructed airway would not impact PFT results because it was not contributing whatsoever. Oxygen saturation on room air at rest was $98 \%$. Because of technical details related to her previous surgery, the patient was not deemed to be a candidate for any further operative attempts at correcting the scoliosis. Therefore, the bronchial obstruction was managed with an indwelling metallic stent inserted in the bronchus intermedius. Although the stent was deployed successfully, the technique was difficult because of the proximity of the right upper lobe orifice to the stenotic segment (Figures $1 \mathrm{~B}$ and $2 \mathrm{~B}$ ).

Stenting resulted in an almost complete re-expansion of the affected lung parenchyma, although there was no significant change in PFT results (Figure 3). Clinically, the chronic cough continued and the patient experienced occasional episodes of mild hemoptysis. There were no episodes of respiratory infection in the year following stent insertion and, thereafter, she has experienced one to two episodes of mild bronchitis per year, diagnosed on the basis of increased cough and a change in sputum, all of which responded readily to oral antibiotics and none of which required hospitalization. Two years after stent insertion, a small nodule of granulation tissue causing mild hemoptysis and partial obstruction of the middle and lower lobes had to be treated with cryotherapy without recurrence. The stent has always been in good position in the bronchus intermedius and no further stent-related complications have occurred.

\section{DISCUSSION}

IS is a complex three-dimensional deformity involving both abnormal flexion and rotation of the thoracic vertebrae (1). Cobb's angle is usually used to describe the geometric severity of IS. It approximately correlates with overall clinical severity (2) although, in reality, the exact relationship between scoliosis and lung function is highly complex.

Scoliosis significantly alters the geometry of the chest and, ultimately, decreases the three-dimensional range of motion of both the thoracic cage and spine during breathing (1). In addition, the deformity places respiratory muscles at a biomechanical disadvantage (2), ultimately leading to decreased compliance of the chest wall and a restrictive syndrome that may significantly impact respiratory function $(1,2)$. The ultimate severity is a function of Cobb's angle, the number

${ }^{1}$ Division of Thoracic Surgery; ${ }^{2}$ Division of Respirology, Hôpital Maisonneuve-Rosemont, University of Montreal, Montreal, Quebec

Correspondence: Dr George Rakovich, Division of Thoracic Surgery, Hôpital Maisonneuve-Rosemont, 5415 boulevard, L'Assomption, Montreal,

Quebec H1T 2M4. Telephone 514-252-3822, e-mail george.rakovich@umontreal.ca 


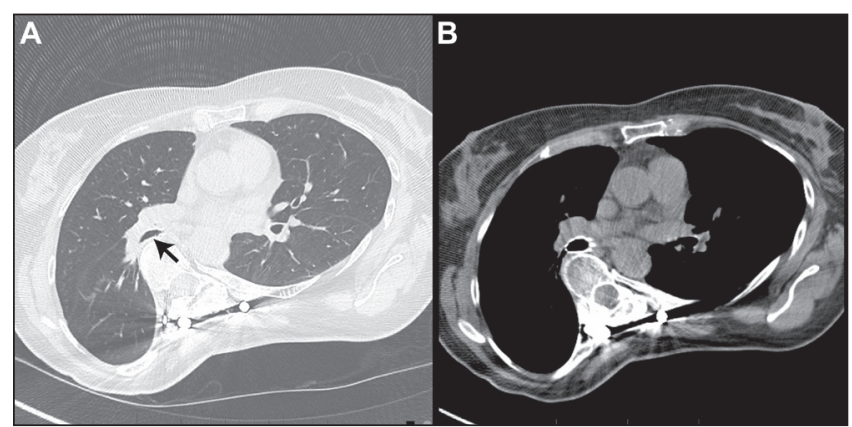

Figure 1) A Computed tomography showing extrinsic compression of the bronchus intermedius (arrow) by a severely scoliotic spine. B Endobronchial stent in the bronchus intermedius, relieving compression and restoring bronchial patency

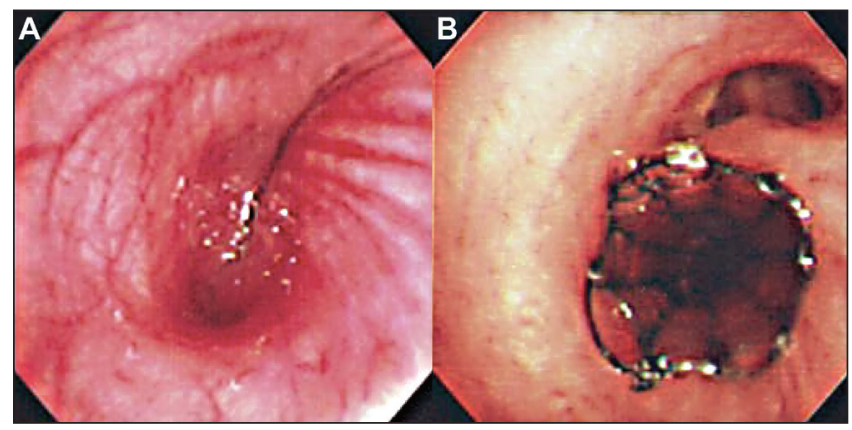

Figure 2) A Bronchoscopy showing compression of the bronchus intermedius by a severely scoliotic spine. B Endobronchial stent in the bronchus intermedius, relieving compression and restoring bronchial patency

of involved vertebrae, the location of the abnormal curvature and the loss of normal thoracic kyphosis (2). Long-standing pulmonary hypoinflation leads to retention of secretions and small airways disease, as well as atelectasis and, eventually, irreversible lung atrophy, further reducing volume (2). Although blood gas levels are often normal at rest, gas exchange may be markedly altered during exercise, with resulting hypoxemia and hypercapnia. Severe scoliosis (Cobb's angle $>70^{\circ}$ ), especially when secondary to neuromuscular disease, may eventually progress to chronic respiratory failure and pulmonary hypertension (2). However, even asymptomatic patients with mild scoliosis may experience significant ventilatory functional impairment during maximal exercise tolerance testing (3).

Although rare, proximal bronchial obstruction may also occur. This may either be due to direct compression by the deviated thoracic spine, or rotation and distortion of the airway because of severely altered thoracic anatomy (4). The patient will usually present with progressive dyspnea and recurrent episodes of localized pulmonary infection. Although evidence is scant, a review of published cases suggests that compression may occur more frequently on the right, especially at the level of the right mainstem bronchus. Cross-sectional imaging will document bronchial compression across the deformed spine, as well as reveal signs of atelectasis or infection in the affected bronchopulmonary segments (5). PFTs may show an obstructive pattern, although the overall picture is also highly dependent on the effects of altered chest wall configuration and mechanics on lung volumes. This likely accounts for the variable findings reported and, in our case, the lack of a clear impact of bronchial stenting on spirometry results despite restoration of bronchial patency (5).

The first step in the management of symptomatic bronchial obstruction is usually correction of the scoliosis (6). A conservative approach using bracing is worth considering in mild cases. Bracing has been used for decades, especially in adolescent scoliosis during the rapid growth phase (7). However, success in stabilizing or improving the scoliosis is modest, may not be permanent and requires the brace

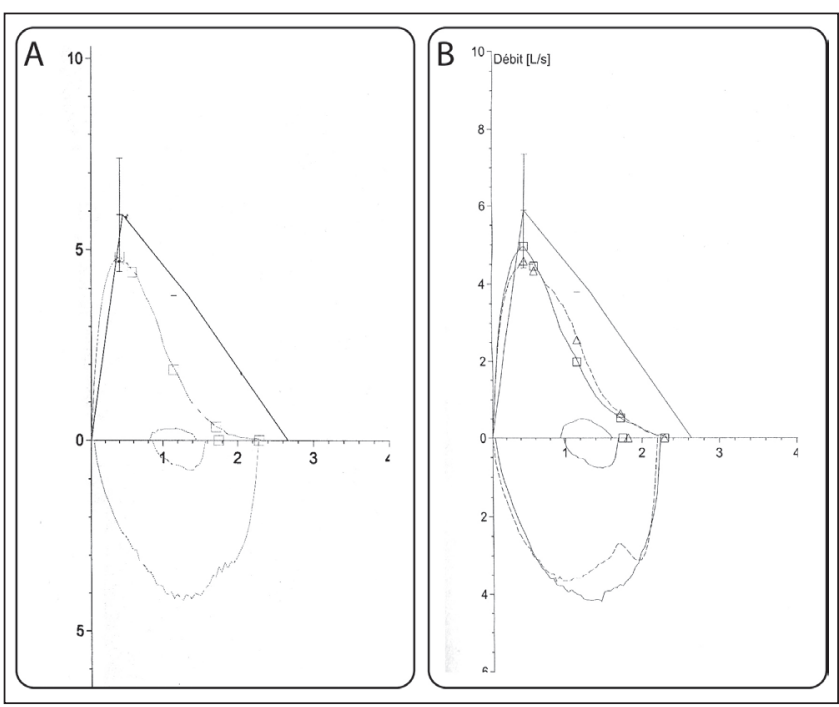

Figure 3) Decreased peak flow and moderate scalloping of the expiratory curve suggest peripheral bronchial obstruction. There is minimal change between the loops before (A) and after bronchial stent insertion (B). This is probably due to the fact that the overall picture is dependent on the relative contribution of altered lung volumes and function in addition to large airways obstruction

to be worn virtually continuously, often resulting in low compliance. Furthermore, the brace itself may worsen pulmonary restriction (2). Other nonsurgical interventions aimed at improving the deformity include exercise, biofeedback and elecrostimulation; however, their effectiveness is limited at best (2).

Use of chest physiotherapy, postural drainage and airway clearance devices have been described in bronchial obstructive syndromes and patients with severe scoliosis, and may be used as ancillary measures (2).

If such a conservative approach fails, surgical correction of the scoliosis may be indicated to lift the bronchial obstruction. A comparable strategy has been used successfully in the treatment of postpneumonectomy syndrome, in which surgical repositioning of a widely displaced mediastinum relieves bronchial compression caused by an impingement of the bronchus between the descending aorta and spine (8). In scoliosis, the decision for surgical correction depends on several factors including the geometry of the scoliosis, age at presentation, severity of symptoms and general quality of life. Although an in-depth discussion of surgical techniques is beyond the scope of the present article, several points can be made. Most of these reliably restore chest wall architecture and correct spinal deformity (9-11). However, the results of surgery on overall pulmonary function are inconsistent and remain controversial (9-11). Most authors agree that spinal fusion through a posterior approach improves both lung volumes (vital capacity and total lung capacity) and function in both the short and long term $(10,11)$. However, anterior approaches to spinal fusion that require thoracotomy as well as thoracoplasty techniques that result in disruption of the chest cavity both tend to cause worsening of lung function $(10,11)$. It is also important to emphasize that there are no reliable predictors of the degree to which anatomical correction will restore bronchial patency (12). Thus, the net result of surgical treatment would depend both on the restoration of bronchial patency and changes in lung volumes and function.

In cases in which symptoms of bronchial obstruction persist, despite optimal correction of the scoliosis, endobronchial stenting has been used successfully $(13,14)$. Stenting usually results in improvement of the obstructive pattern observed on PFTs, decreased evidence of volume loss on pulmonary imaging, improved gas exchange and improved dyspnea. However, self-expandable metal stents are not without risks and should be used cautiously. When treating benign disease, stents are usually reserved as a last resort in inoperable patients. 
Indwelling stents may lead to a variety of complications, which may require remediation by interventional bronchoscopy $(15,16)$. Granulation tissue is the most frequent complication, occurring in approximately $40 \%$ to $50 \%$ of cases; it is usually managed with cautery, laser ablation, cryotherapy or balloon dilation $(15,16)$. Intractable granulation may require stent removal in $12.9 \%$ of cases $(15,16)$. Migration may occur in up to $5 \%$ of cases, and stent metal fatigue or fracture in a further $3 \%$ to $5 \%(15)$. Although the patient we describe is doing well, studies have shown that $25 \%$ of stents inserted for benign disease may eventually require removal for intractable complications (16). Although the stents are designed to be permanent, removal is still often possible, even after several years, but requires an experienced team and may be technically challenging (16)

Once the decision to use stenting has been made, these patients should be followed closely. Although we do not have a rigid poststenting surveillance protocol, we perform follow-up bronchoscopies periodically and as needed, on a case-by-case basis.

DISCLOSURES: The authors have no financial disclosures or conflicts on interest to declare.

\section{REFERENCES}

1. Leong JC, Lu WW, Luk KD, Karlberg EM. Kinematics of the chest cage and spine during breathing in healthy individuals and in patients with adolescent idiopathic scoliosis. Spine 1999;24:1310-5

2. Koumbourlis AC. Scoliosis and the respiratory system. Paediatr Respir Rev 2006;7:152-60.

3. Barrios C, Pérez-Encinas C, Maruenda JI, Laguía M. Significant ventilatory functional restriction in adolescents with mild or moderate scoliosis during maximal exercise tolerance test. Spine 2005;30:1610-5.

4. de Torres García I, de Cabo Moreno P, Ramírez AM. Extrinsic bronchial obstruction caused by scoliosis. Spine 2013;38:E840-3.

5. Karoll M, Hernandez RJ, Wessel HU. Computed tomography diagnosis of bronchial compression by the spine after surgical correction of scoliosis. Pediatr Radiol 1984;14:335-6.

6. Weiss HR, Goodall D. The treatment of adolescent idiopathic scoliosis (AIS) according to present evidence. A systematic review. Eur J Phys Rehabil Med 2008;44:177-93.

7. Kennedy JD, Robertson CF, Hudson I, Phelan PD. Effect of bracing on respiratory mechanics in mild idiopathic scoliosis. Thorax 1989;44:548-53.

8. Rakovich G, Bussières J, Fréchette E. Postpneumonectomy syndrome. Multimed Man Cardiothorac Surg 2009;2009(831):mmct s.2008.003475. doi: 10.1510/mmcts.2008.003475.

9. Mayer $\mathrm{OH}$, Redding G. Early changes in pulmonary function after vertical expandable prosthetic titanium rib insertion in children with thoracic insufficiency syndrome. J Pediatr Orthop 2009;29:35-8.
Post-test:

- What is the most common cause of chronic dyspnea in patients with IS?

Patients with symptomatic IS may have marked anatomical alteration causing a reduction in lung volumes and decreased efficiency of respiratory muscles. Therefore, a restrictive pattern is most commonly seen in these patients. Obstructive patterns are less frequent.

- What are the options for treating bronchial obstruction caused by scoliosis?

The first step in the management of symptomatic bronchial obstruction is usually correction of the scoliosis. A conservative approach with bracing and physiotherapy is reasonable in mild-to-moderate cases (Cobb's angle $\leq 70^{\circ}$ ) although the likelihood of success is modest. In cases of severe scoliosis (Cobb's angle $>70^{\circ}$ ) or if a conservative approach fails, surgical correction of the scoliosis may be considered to lift the bronchial obstruction. Endobronchial stenting is a less invasive alternative that has shown efficacy in cases in which other options were not possible, although it should be considered with caution because of the potential for long-term complications.

10. Lenke LG, White DK, Kemp JS, Bridwell KH, Blanke KM, Engsberg JR. Evaluation of ventilatory efficiency during exercise in patients with idiopathic scoliosis undergoing spinal fusion. Spine 2002;27:2041-5.

11. Pehrsson K, Danielsson A, Nachemson A. Pulmonary function in adolescent idiopathic scoliosis: A 25 year follow up after surgery or start of brace treatment. Thorax 2001;56:388-93.

12. Sakić K, Pećina M, Pavicić F. Cardiorespiratory function in surgically treated thoracic scoliosis with respect to degree and apex of scoliotic curve. Respiration 1992;59:327-31.

13. Al-Kattan K, Simonds A, Chung KF, Kaplan DK. Kyphoscoliosis and bronchial torsion. Chest 1997;111:1134-7.

14. van Ooij A, van Belle A, Timmer R, van Rhijn L. The destroyed lung syndrome: Report of a case after Harrington rod instrumentation and fusion for idiopathic scoliosis. Spine 2002;27:E337-41.

15. Madden BP, Loke TK, Sheth AC. Do expandable metallic airway stents have a role in the management of patients with benign tracheobronchial disease? Ann Thorac Surg 2006;82:274-8.

16. Noppen M, Stratakos G, D'Haese J, Meysman M, Vinken W. Removal of covered self-expandable metallic airway stents in benign disorders: Indications, technique, and outcomes. Chest 2005;127:482-7. 


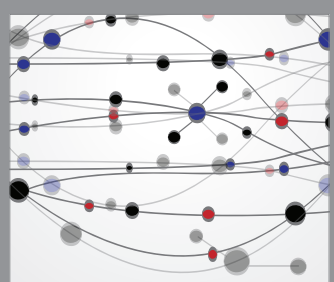

The Scientific World Journal
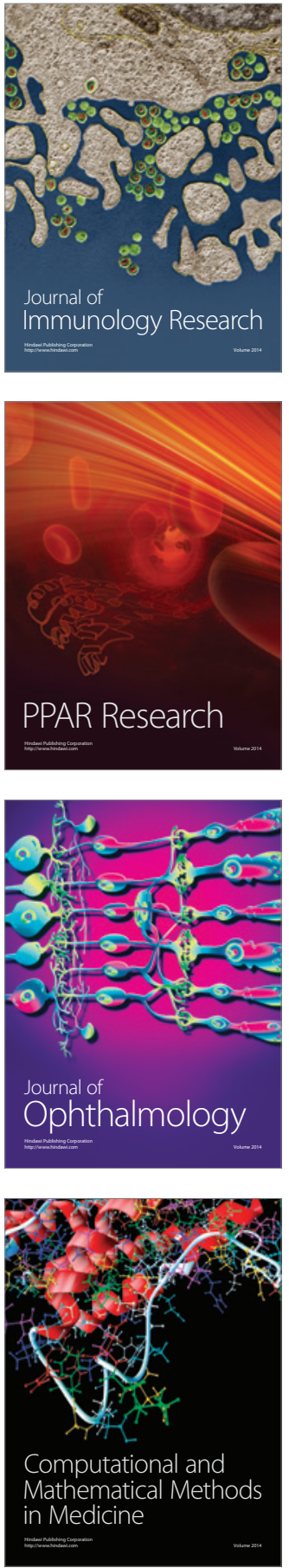

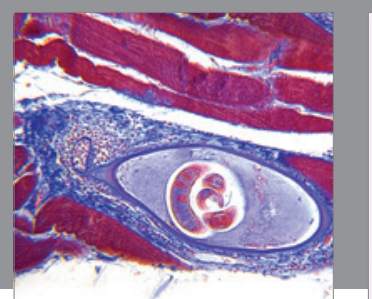

Gastroenterology Research and Practice

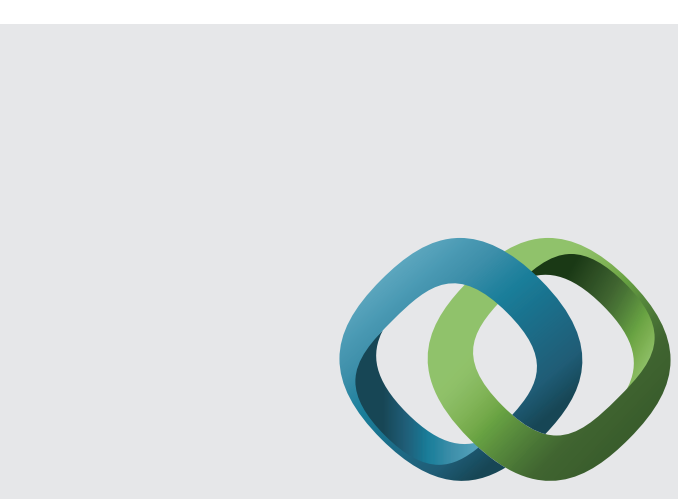

\section{Hindawi}

Submit your manuscripts at

http://www.hindawi.com
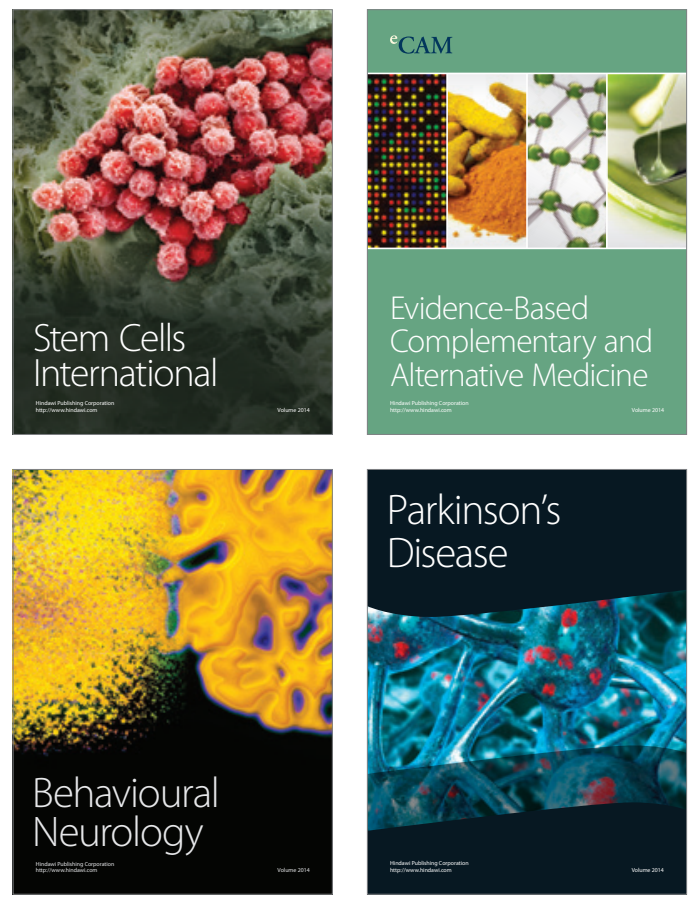
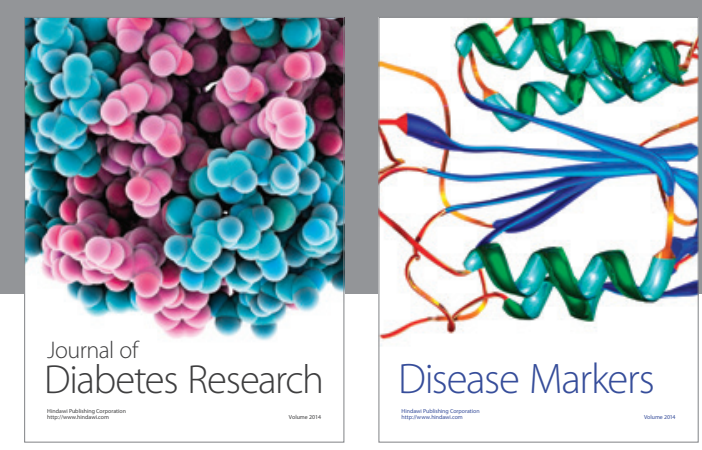

Disease Markers
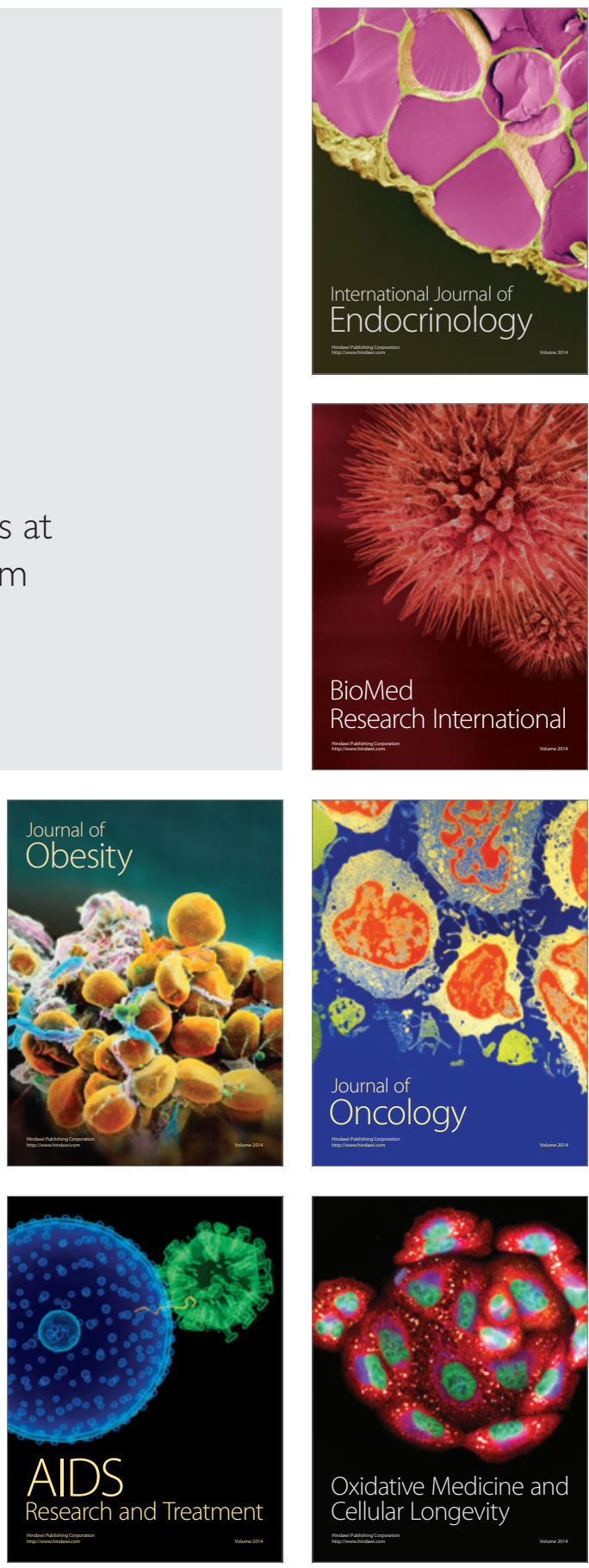